\title{
THE ROLE OF TADALAFIL AND TAMSULOSIN ALONE AND IN COMBINATION THERAPY IN LOWER URETERIC STONE EXPULSION
}

\author{
Girish T. D1, Syed Zahid Raza 2 , Vijaya Kumar R3 , K. M. Madappa ${ }^{4}$
}

${ }^{1}$ Associate Professor, Department of Urology, JSSMC, Mysore.

${ }^{2}$ Senior Resident, Department of Urology, JSSMC, Mysore.

${ }^{3}$ Assistant Professor, Department of Urology, JSSMC, Mysore.

4 Professor and HOD, Department of Urology, JSSMC, Mysore.

\begin{abstract}
The incidence of urinary stones is increasing day by day. The incidence rate of lower ureteric stones is $70 \%$. Medical expulsive therapy developed after an understanding of various pathophysiologic basis for urinary stones. Alpha- 1 adrenergic receptor antagonists are most commonly used, which act by creating an increased pressure gradient around the stone, which propels the stones out. Recently, phosphodiesterase-5 inhibitors like tadalafil have been shown to act by a CGMP signaling pathway to cause smooth muscle relaxation and help in stone expulsion.
\end{abstract}

\section{OBJECTIVES}

To compare the safety and efficacy of tamsulosin, tadalafil, and combination of tamsulosin with tadalafil as medical expulsive therapies for lower ureteric stones.

\section{MATERIALS AND METHODS}

A total of 90 patients who presented with distal ureteric stones between September 2013 and August 2015 were simply randomised equally based on a computer generated table into three groups, group A received tamsulosin, group B patients received tadalafil alone, and group $\mathrm{C}$ patients received a combination of tamsulosin with tadalafil. Therapy was given for a maximum of 4 weeks. The stone expulsion rate, time to stone expulsion, analgesic use, number of hospital visits for pain, followup endoscopic treatment, and adverse effects of the drugs were noted. Statistical analyses were done by using Student's t-test and chi-square test.

\section{RESULTS}

There was a higher expulsion rate $78 \%$ in group C, which received combination therapy compared to $75 \%$ in group B and $70 \%$ in group A. There was an increase in expulsion rate in patients with combination therapy, though statistical significance could not be demonstrated in this sample size. The analgesic requirement and hospital visits due to colic were decreased significantly in the combination therapy group and time to expulsion was also lesser in group C compared to group A and B. There were no serious adverse effects noted.

\section{CONCLUSION}

Medical expulsive therapy for distal ureteric stones using combination of tamsulosin and tadalafil is safe and efficacious compared to monotherapy with either of the drugs alone. It significantly decreases the analgesic dose requirement and aids in pain relief as well.

\section{KEYWORDS}

Tadalafil, Tamsulosin, Distal Ureteral Stones.

HOW TO CITE THIS ARTICLE: Girish TD, Raza SZ, Kumar RV, et al. The role of tadalafil and tamsulosin alone and in combination therapy in lower ureteric stone expulsion. J. Evolution Med. Dent. Sci. 2016;5(77):5746-5749, DOI: 10.14260/jemds/2016/1295

\section{INTRODUCTION}

Urolithiasis is an ailment affecting $12 \%$ of world population. ${ }^{1}$ Symptomatic urolithiasis represents the most common condition observed by urologists in emergency setting, $70 \%$ of which are located in the lower third of ureter.

Transport of stones from kidney into the bladder and their movement through the ureter is accompanied by three basic factors.

1. Spasm of smooth muscle.

2. Submucosal oedema.

3. Pain.

Financial or Other, Competing Interest: None.

Submission 21-07-2016, Peer Review 14-08-2016,

Acceptance 22-08-2016, Published 26-09-2016.

Corresponding Author:

Dr. Syed Zahid Raza,

\#109, 3rd Main Road,

Bannimantap 'C' Layout, Mysore-570015.

E-mail: syed.zahid.raza@gmail.com

DOI: $10.14260 /$ jemds $/ 2016 / 1295$
The factors determining the passage of stone are their size, configuration, and smooth muscle activity of the ureter. ${ }^{2}$ The greatest obstacle in the passage is usually the terminal part of the ureter.

Ureteric calculi of any size are often associated with renal obstruction. Hence, care must be taken to prevent irreversible damage to the kidney.

Although, minimally-invasive treatments for lower ureteral stones are efficacious, they are not free of complications and are associated with high cost. Medical expulsion therapy has recently emerged as an alternative strategy for the initial management of small distal ureteral stones. ${ }^{3,4}$

Currently, alpha-1 adrenergic receptor antagonists represent the treatment of choice for lower urinary tract symptoms as shown in many randomised controlled clinical trials.5,6,7 Alpha- 1 adrenergic receptors are present in ureteric smooth muscles and antagonists inhibit basal tone, peristaltic frequency, and ureteral contractions even in the intramural tract. 
Recently, a newer phosphodiesterase-5 (PDE-5) inhibitor, tadalafil has emerged, which acts on NO/cGMP pathway of smooth muscles resulting in increased levels of cyclic guanosine monophosphate causing ureteric relaxation. ${ }^{8}$ Tadalafil also relaxes, increases the blood flow to the corpus cavernosum, and enhances erectile function by increasing the amount of cGMP.

\section{AIMS AND OBJECTIVES}

To compare the efficacy of tadalafil alone and in combination with tamsulosin in expulsion rate and expulsion time of lower ureteric calculus.

To evaluate the effect of these drugs on frequency of analgesic use.

\section{MATERIALS AND METHODS}

This study was conducted in the Department of Urology at JSS Medical College, Mysore, from September 2013 to August 2015.

Patients with symptoms suggestive of ureteral stones on outpatient basis were evaluated using standard ultrasonography of KUB or CT KUB. Following confirmation, patients with distal ureteral stones were included in the study.

The study included 90 patients who were simply randomised into three equal groups of patients by use of a computer-generated table.

Group 1: Received tadalafil 5 mg O.D.

Group 2: Received combination of tadalafil and tamsulosin O.D.

Group 3: Received tamsulosin 0.4 mg O.D.

All patients received analgesic diclofenac (50/75 mg) orally/parenterally as needed. Duration of therapy was no longer than 2 weeks. The study was reviewed by the Hospital Ethics Committee.

\section{Inclusion Criteria}

All patients evaluated in JSS Medical College Hospital with ureteric colic due to radiologically-proven distal ureteral stones less than or equal to $10 \mathrm{~mm}$ and who were managed conservatively.

\section{Exclusion Criteria}

1. Stone larger than $10 \mathrm{~mm}$.

2. UTI.

3. Severe hydroureteronephrosis on USG/urinoma.

4. Co-morbid conditions such as diabetes, altered renal parameters, and history of cardiac disease.

5. Multiple ureteral stones.

6. Known sensitivity to alpha blockers and PDE5 inhibitors.

7. Pregnancy.

\section{Outcome Measures}

1. Expulsion rate.

2. Expulsion time.

3. Dose of analgesics used.

Objective documentation of stone expulsion was done based on followup renal ultrasonography. Patients who did not pass the stone spontaneously were subjected to surgical intervention. Data was analysed using SPSS version 17.

\section{RESULTS}

Out of 90 patients included in the study who were subsequently divided into further three groups based on the drug they received for medical expulsion of stones, the maleto-female distribution among these groups was found to be $3: 2,7: 3$, and $2: 1$ in group 1,2 , and 3 respectively. The $P$ value is 0.709. (Table 1 ).

The average age at which the diagnosis of ureteric stone disease was made was found to be 36 years. The $P$ value is 0.096 (Table 2).

The average size of stone expelled in group 1 was $6.26 \mathrm{~mm}$, group 2 was $6.16 \mathrm{~mm}$, and group 3 was $6.03 \mathrm{~mm}$. The P value is 0.834 . (Table 3 ).

Among 90 patients included in the study, 66 patients expelled stones following medical therapy, 22 patients in group 1 responded to the treatment, 23 in group 2, and 21 patients in group 3 . The remaining 24 patients underwent ureteroscopy and stone removal. The $P$ value is 0.049 , which is significant. (Table 4).

The average time taken for stone expulsion after starting treatment was an average of 4.15 days for group 1, 3.6 days for group 2, and 4 days for group 3 . The P value is 0.545 . (Table 5).

The analgesic used for pain management was NSAIDs (diclofenac). The average dose required by the patients in all the three groups during the therapy was compared. Patients in group 1 required $400 \mathrm{mg}$ of diclofenac totally. Group 2 required $346 \mathrm{mg}$ and group 3 required $476 \mathrm{mg}$ of diclofenac. The $P$ value is 0.044 . (Table 6).

\begin{tabular}{|c|c|c|c|c|c|c|}
\hline & \multicolumn{3}{|c|}{ Group } & \multirow{2}{*}{ Total } \\
\hline & & & Group 1 & Group 2 & Group 3 & \\
\hline \multirow{4}{*}{ Sex } & \multirow[b]{2}{*}{ M } & Count & 18 & 21 & 20 & 59 \\
\hline & & $\begin{array}{l}\text { \% Within } \\
\text { Group }\end{array}$ & $60.0 \%$ & $70.0 \%$ & $66.7 \%$ & $65.6 \%$ \\
\hline & \multirow[b]{2}{*}{$\mathrm{F}$} & Count & 12 & 9 & 10 & 31 \\
\hline & & $\begin{array}{c}\text { \% Within } \\
\text { Group }\end{array}$ & $40.0 \%$ & $30.0 \%$ & $33.3 \%$ & $34.4 \%$ \\
\hline \multirow{2}{*}{\multicolumn{2}{|c|}{ Total }} & Count & 30 & 30 & 30 & 90 \\
\hline & & $\begin{array}{l}\text { \% Within } \\
\text { Group }\end{array}$ & $100.0 \%$ & $100.0 \%$ & $100.0 \%$ & $100.0 \%$ \\
\hline
\end{tabular}

\begin{tabular}{|c|c|c|}
\hline & $\mathbf{N}$ & Mean \\
\hline Group 1 & 30 & 32.9667 \\
\hline Group 2 & 30 & 39.1667 \\
\hline Group 3 & 30 & 37.3000 \\
\hline Total & 90 & 36.4778 \\
\hline
\end{tabular}

\begin{tabular}{|c|c|c|}
\hline & N & Mean \\
\hline Group 1 & 30 & 6.2667 \\
\hline Group 2 & 30 & 6.1667 \\
\hline Group 3 & 30 & 6.0333 \\
\hline Total & $\mathbf{9 0}$ & $\mathbf{6 . 1 5 5 6}$ \\
\hline \multicolumn{2}{|c|}{ Table 3: Size of Stone Expelled } \\
\hline
\end{tabular}




\begin{tabular}{|c|c|c|c|c|c|c|}
\hline \multicolumn{2}{|c|}{} & \multicolumn{3}{c|}{ Group } & \multirow{2}{*}{ Total } \\
\cline { 3 - 7 } \multicolumn{2}{|c|}{} & Group 1 & Group 2 & Group 3 & \\
\hline \multirow{3}{*}{ Expulsion } & \multirow{2}{*}{ No } & Count & 8 & 7 & 9 & 24 \\
\cline { 2 - 7 } & $\%$ & $26.7 \%$ & $23.3 \%$ & $30.0 \%$ & $26.7 \%$ \\
\cline { 2 - 6 } & \multirow{2}{*}{ Yes } & Count & 22 & 23 & 21 & 66 \\
\cline { 3 - 7 } & & $73.3 \%$ & $76.7 \%$ & $70.0 \%$ & $73.3 \%$ \\
\hline \multirow{2}{*}{ Total } & Count & $\mathbf{3 0}$ & $\mathbf{3 0}$ & $\mathbf{3 0}$ & $\mathbf{9 0}$ \\
\cline { 2 - 6 } & $\mathbf{9}$ & $\mathbf{1 0 0 . 0 \%}$ & $\mathbf{1 0 0 . 0} \%$ & $\mathbf{1 0 0 . 0 \%}$ & $\mathbf{1 0 0 . 0 \%}$ \\
\hline \multicolumn{6}{|c|}{ Table 4: Stone Expulsion Rate } \\
\hline
\end{tabular}

\begin{tabular}{|c|c|c|c|}
\hline & N & Mean & Std. Deviation \\
\hline Group 1 & 22 & 4.14 & 2.031 \\
\hline Group 2 & 23 & 3.61 & 1.500 \\
\hline Group 3 & 21 & 4.05 & 1.564 \\
\hline Total & $\mathbf{6 6}$ & $\mathbf{3 . 9 2}$ & $\mathbf{1 . 7 0 3}$ \\
\hline \multicolumn{2}{|c|}{ Table 5: Average Time to Stone Expulsion } \\
\hline
\end{tabular}

\begin{tabular}{|c|c|c|c|}
\hline & N & Mean & Std. Deviation \\
\hline Group 1 & 30 & 406.6667 & 182.17240 \\
\hline Group 2 & 30 & 346.6667 & 201.68828 \\
\hline Group 3 & 30 & 476.6667 & 209.87818 \\
\hline Total & $\mathbf{9 0}$ & $\mathbf{4 1 0 . 0 0 0 0}$ & $\mathbf{2 0 3 . 1 6 3 1 9}$ \\
\hline \multicolumn{4}{|c|}{ Table 6: Analgesic Requirement } \\
\hline
\end{tabular}

\section{DISCUSSION}

Ureteric calculi are one of the very common diseases that a urologist encounters. The aetiology of stone disease can be attributed to diet, lifestyle, recurrent UTIs.

The factors influencing spontaneous expulsion are stone location, size, number, and structure, ureteral spasm, mucosal oedema or inflammation, and ureteral anatomy. Therefore, the use of medical therapy is justifiable to reduce oedema, reduce spasm, and relax the smooth muscles for stone expulsion.

The treatment of this disease has been evolving with introduction of new drugs and techniques. But, among the medical line of management, alpha-adrenergic antagonists have been studied in depth and used widely since a long time.

According to data in the literature, the distal ureteric stone expulsion rate with the watchful waiting approach is $25 \%$ to $54 \%$ with a mean expulsion time of greater than 10 days and considerable analgesic requirement even for stones $<4 \mathrm{~mm}$.

The newer drugs like PDE5 inhibitors have recently gained popularity for their use in the treatment of lower ureteric stones of size less than $10 \mathrm{~mm}$.

To increase the expulsion rate and reduce the analgesic requirement, there is a great deal of enthusiasm for adjuvant pharmacological interventions. Conservative therapy is considered especially in cases of distal ureteral stones. In 2005 Sigala et al found that $\alpha-1 \mathrm{D}$ and $\alpha-1 \mathrm{~A}$ adrenoreceptors are present in significantly larger amounts than $\alpha-1 B$ adrenoreceptors in the human ureter. Therefore, clinical studies have been conducted to investigate the effect of the combined $\alpha-1 \mathrm{~A}-$ and $\alpha$-1D-selective antagonist tamsulosin on distal ureteral stone expulsion. ${ }^{6}$

In a randomised study conducted by Jayant et al in 2014, comparing the efficacy of tamsulosin alone and in combination with tadalafil in lower ureteric stones in 244 patients concluded that stone expulsion rate was higher in the group, which received tadalafil and tamsulosin $(\mathrm{P}=0.031)$ compared to tamsulosin monotherapy with no serious adverse effects.
Tadalafil also showed an improvement in erectile dysfunction. ${ }^{7}$

We decided to use tadalafil on the basis of reports by Gratzke et al who demonstrated the role of phosphodiesterase inhibitors in relaxation of ureteric muscles in the rank order of vardenafil $>$ sildenafil $>$ tadalafil. Because tadalafil is more selective than sildenafil for PDE5 than PDE6 receptors, which are present in the retina, visual problems are less likely. Tadalafil has the longest duration of action ( -36 hours with a half-life of 17.5 hours) among the current PDE5 inhibitors and its activity is unaffected by meals. Vardenafil has a structure similar to that of sildenafil, but the structure of tadalafil is quite different. To keep adverse effects to a minimum, we used tadalafil in smaller doses $(10 \mathrm{mg})$. Another reason to choose tadalafil with tamsulosin was because Kloner et al demonstrated that the combination of tamsulosin and tadalafil did not show significant haemodynamic changes. 9 This combination had also been used for the treatment of lower urinary tract symptoms associated with benign prostatic hyperplasia by Bechara et al and has shown significant improvements in pain by the relaxation of the bladder, urethra, and prostate and was the basis of this pilot study. ${ }^{10}$

In another study conducted by Bos et al titled, 'update on medical expulsive therapy for distal ureteral stones: beyond alpha-blockers' concluded that corticosteroid therapy in adjunct to alpha-blocker therapy is effective in improving expulsion rates. PDE5 inhibitors did not show significantly higher expulsion rates compared to alpha-blockers and calcium channel blockers remain inferior to alpha-blockers. ${ }^{11}$

Colicky pain in ureteral stones occurs owing to an increase in intraureteral pressure above the site of ureteral obstruction. Kinnman et al found that $\alpha$-blockade may relieve ureteric colic by blocking the $\mathrm{C}$-fibers responsible for mediating pain. ${ }^{12}$ Use of $\alpha$-blockers for expulsion of ureteric stones probably decreases the analgesic requirement in two ways: Expulsion of stones and blockade of C-fibers. Thus, it is difficult to assess, which of these maybe primarily responsible for decreasing the analgesic requirement.

In our study, there was no significant difference among age and sex distribution.

In the comparison of expulsion rate, group 2 patients who received a combination of tadalafil and tamsulosin showed the highest expulsion rate $76 \%$ compared to $73 \%$ and $70 \%$ of group 1 and 3 , respectively.

A total of 24 patients did not respond to medical expulsion therapy and underwent further surgical management.

In our study, the analgesic requirement in group B was significantly less than that in group A and C. This excellent pain control observed in group B patients was also demonstrated by the lesser need for hospitalisation for colic during the study. These effects of the combined use of tamsulosin and tadalafil on the ureter were probably due to a decrease in the frequency and amplitude of the phasic peristaltic contractions that accompany ureteric obstruction, i.e., an improved antispasmodic effect.

Our results did not reach statistical significance probably because of the small sample size. This study was undertaken as a pilot project. Thus, because such studies have not been conducted earlier, we could not perform a formal sample size calculation.

There were no serious adverse effects noted in any of the groups. The reported side effects were minimal in our study 
probably because of the healthy study population and the lack of any associated comorbidity.

The limitation of our study was the small sample size, but the study is still valuable as a pilot study. Furthermore, to our knowledge, this is the comparison study of tamsulosin with tamsulosin and tadalafil and produced some insightful results that should be tested in future studies.

\section{CONCLUSION}

PDE5 inhibitors like tadalafil are equally efficacious in expulsion of lower ureteric stones of size less than $10 \mathrm{~mm}$ either alone or in combination with alpha-adrenergic antagonists without any serious adverse effects. The results of this study indicate that the addition of tadalafil with tamsulosin increases the ureteric stone expulsion rate, although not significantly so and provides significant control of pain, a significantly lesser analgesic requirement and fewer hospital visits. Also, the prescription of tadalafil in cases of erectile dysfunction with the development of lower ureteric stones may provide an additional advantage in the expulsion of stones.

\section{REFERENCES}

1. Pak CY. Kidney stones. Lancet 1998;351(9118): 1797-801.

2. Lang RJ, Exintaris B, Teele ME, et al. Electrical basis of peristalsis in the mammalian upper urinary tract. Clin Exp Pharmacol Physiol 1998;25(5):310-21.

3. Tzortzis V, Mamoulakis C, Rioja J, et al. Medical expulsive therapy for distal ureteral stones. Drugs 2009;69(6): 677-92.
4. Hollingsworth JM, Rogers MAM, Kaufman SR, et al. Medical therapy to facilitate urinary stone passage: a meta-analysis. Lancet 2006;368(9542):1171-9.

5. Morita $\mathrm{T}$, Ando $\mathrm{M}$, Kihara $\mathrm{K}$, et al. Function and distribution of autonomic receptors in canine ureteral smooth muscle. Neurourol Urodyn 1994;13(3):315-21.

6. Sigala S, Dellabella M, Milanese G, et al. Evidence for the presence of alpha-1 adrenoceptor subtypes in the human ureter. Neurourol Urodyn 2005;24(2):142-8.

7. Kumar S, Jayant K, Agrawal S, et al. Comparative efficacy of tamsulosin versus tamsulosin with tadalafil in combination with prednisolone for the medical expulsive therapy of lower ureteric stones: a randomised trial. Korean J Urol 2014;55(3):196-200.

8. Jayant K, Agrawal MM, Kumar S, et al. Role of tamsulosin, tadalafil and silodosin as the medical expulsive therapy in lower ureteric stones: a randomised trial. Int J Urol 2014;21(10):1012-5.

9. Kloner RA, Jackson G, Emmick JT, et al. Interaction between the phosphodiesterase 5 inhibitor, tadalafil, and 2 alpha blockers, doxazosin, and tamsulosin in healthy normotensive men. J Urol 2004;172(5 pt 1):1935-40.

10. Bechara A, Romano S, Casabe A, et al. Comparative efficacy assessment of tamsulosin vs. tamsulosin plus tadalafil in the treatment of LUTS/BPH pilot study. J Sex Med 2008;5(9):2170-8.

11. Bos D, Kapoor A. Update on medical expulsive therapy for distal ureteral stones: beyond alpha blockers. Can Urol Assoc J 2014;8(11-12):442-5.

12. Kinnman E, Nygards EB, Hansson P. Peripheral alpha adrenoreceptors are involved in the development of capsaicin-induced ongoing and stimulus evoked pain in humans. Pain 1997;69(1-2):79-85. 